\title{
A regulação das políticas de educação na União Europeia e os desafios para a Educação a Distância no ensino superior: uma perspetiva crítica e uma proposta de investigação
}

\author{
The regulation of education policies in the European Union and the challenges \\ for Distance Education in higher education: a critical perspective and a \\ research proposal \\ La regulación de las políticas de educación en la Unión Europea y los desafíos \\ para la Educación a Distancia en la enseñanza superior: una perspectiva crítica \\ y una propuesta de investigación
}

CLÁUDIA NEVES

\begin{abstract}
Resumo: Neste artigo, procuramos sistematizar algumas reflexões em torno das tendências políticas para o ensino superior na Europa, e o papel que a educação a distância pode assumir nessa estratégia. Procuraremos entender a interpretação do governo português dessas orientações e como regulamenta a educação a distância no ensino superior. Terminamos com uma leitura crítica do enquadramento político português para a educação a distância no ensino superior e uma proposta de desenvolvimento futuro de uma investigação que procure compreender diferentes posicionamentos políticos em diversos países da União Europeia, relativamente às estratégias políticas para a educação a distância no ensino superior.
\end{abstract}

Palavras-chave: Educação a distância, Ensino Superior, Regulação de Políticas Educativas, União Europeia.

\begin{abstract}
In this article, we seek to systematize some reflections on the political trends for higher education in Europe, and the role that distance education can play in this strategy. We seek to understand the Portuguese government's interpretation of these guidelines and how it regulates distance education in higher education. We end up with a critical reading of the Portuguese policy framework for distance education in higher education, and with a proposal for future development of an investigation that seeks to understand different political positions in different countries of the European Union, regarding the political strategies for distance education, in higher education.
\end{abstract}

Keywords: distance education, higher education, regulation of educational policies, European Union.

Resumen: En este artículo, tratamos de sistematizar algunas reflexiones acerca de las tendencias políticas para la educación superior en Europa y el papel que la educación a distancia puede asumir en esa estrategia. Buscaremos entender la interpretación del gobierno portugués con relación a esas orientaciones y cómo regula la educación a distancia en la educación superior. Terminamos con una 
lectura crítica del marco político portugués para la educación a distancia en la educación superior y una propuesta para el desarrollo futuro de una investigación que busque comprender diferentes posiciones políticas, en varios países de la Unión Europea, sobre las estrategias políticas para la educación a distancia en la educación superior.

Palabras clave: Educación a distancia, Educación superior, Regulación de Políticas Educativas, Unión Europea.

\section{A EDUCAÇÃO NA UNIÃO EUROPEIA E OS INSTRUMENTOS DE REGULAÇÃO POLÍTICA}

Desde os seus tratados fundadores até à época atual, a educação e a formação foram sendo alvo de várias iniciativas que foram reconfigurando o seu enquadramento jurídico na União Europeia (UE). A partir da ausência inicial de qualquer referência à educação nos tratados que fundaram a União Europeia, até ao desenvolvimento de uma dimensão europeia da educação, foram sendo cada vez mais desenvolvidas iniciativas e programas que reconfiguram e influenciam os sistemas educativos dos Estados-membros desta união de países.

O termo "união", refere-se a algo que é tecido em comum, que faz parte de um mesmo todo. A União Europeia (UE), ao longo de toda a sua história, teve com principal objetivo unir um conjunto de Estados em torno de objetivos comuns, por forma a torná-los mais fortes e competitivos.

Sendo que uma das principais características da União Europeia é a sua diversidade linguística e cultural característica de cada Estado-Membro, os seus sistemas de educação e formação mantêm um certo isolamento entre si, aplicando regras diferentes, qualificações e currículos diferentes, e regimes de formação diferentes. Cada Estado-Membro pretende preservar esta diversidade. Mas, tem vindo a crescer cada vez mais uma necessidade de cooperação e mobilidade entre os Estados-Membros, no que diz respeito à Educação e Formação, por forma a que os cidadãos possam beneficiar desta diversidade. É neste sentido que a União Europeia tem vindo a desenvolver os seus trabalhos no campo da Educação e Formação, nos últimos 30 anos.

No domínio da Educação e da Formação o papel da União Europeia é de apoiar as medidas nacionais de forma a que todos consigam dar resposta aos desafios que são considerados comuns. Nesse sentido desenvolveu-se um quadro estratégico para a educação e formação (denominado Educação e Formação 2020), que é comum a todos os Estados-membros e que apresenta um conjunto de metas de referência para que os países orientem as suas estratégias 
políticas. Ressalva-se que, na União Europeia, em algumas áreas, como é o caso da Educação, cada país tem autonomia política nos seus sistemas de educação e formação, sendo que o papel da União Europeia é apenas coordenar e apoiar as diversas políticas no sentido de fazer face aos desafios que comuns a tosos como o envelhecimento populacional, a qualificação da mão-de obra, a competitividade económica e tecnológica, etc. Quer o conteúdo e os programas, quer a organização dos sistemas de educação e formação são da responsabilidade de cada Estado-Membro. O princípio da "subsidiariedade" dá à União Europeia, enquanto instituição, a capacidade de apoiar e complementar a ação de cada Estado-Membro em determinados domínios da Educação e da Formação.

Com este enquadramento estratégico a União Europeia desenvolve um conjunto de iniciativas e programas para promover o intercâmbio de boas práticas e aprendizagem mútua, ao mesmo tempo que recolhe e monitoriza todos os avanços dos diversos sistemas de educação e formação dos seus Estados-membros. Através de um conjunto de peritos e especialistas, desenvolveram-se grupos de trabalhos que auxiliam a União Europeia na construção de instrumentos comuns e de orientações políticas.

Em 2014, a Comissão Europeia e os países da União Europeia, através da análise de um conjunto de estudos, relatórios, contribuições e avaliações, fizeram um balanço dos progressos realizados desde 2012 e definiram as próximas prioridades para a cooperação europeia no domínio da educação. Foram assim propostas seis novas prioridades a atingir até ao ano de 2020.

Há vários autores que têm uma visão muito crítica desta "forma" de fazer política e da aparente "liberdade" dos Estados-membros definirem as suas próprias estratégias no seio dos seus sistemas Educativos.

Para refletirmos um pouco sobre estas visões críticas introduzimos, primeiro, o conceito de regulação para compreendermos melhor a ideia de que existe um complexo sistema de regulações a diferentes níveis e executadas por diferentes atores, que confrontam entre si lógicas e interesses diferentes.

Existem vários níveis de regulação que resultam em diferentes efeitos nos modos de regulação política, e existem atores que protagonizam estes vários níveis e modos, que variam de acordo com o seu nível de implicação na formulação da política educativa e pela sua capacidade de regulação em relação aos seus membros. Ioannidou (2007), centra-se na análise dos atores do nível transnacional e apresenta-nos três grupos de atores: 
a) Atores internacionais - como a UNESCO ou a OCDE, que são organizações intergovernamentais sem capacidades de regulação e controle sobre os seus membros, tendo apenas poder para a definição de uma agenda para a educação que propõem, acabando por assumir um papel de grande influência na definição das políticas educativas;

b) Organizações supranacionais - como a União Europeia, que têm capacidades de regulação sobre os seus membros e têm também algum poder legal para moldar políticas em algumas áreas. A União Europeia não tem poder explícito sobre a educação dos seus Estados-membros, mas exerce uma enorme influência sobre a definição das suas políticas educativas;

c) Organizações não-governamentais - como a European Educational Research Association, que operam enquanto redes auto-organizadas de profissionais sem interferência nas políticas dos governos.

Como referimos anteriormente, a União Europeia assume o papel de complementar a ação dos Estados-membros em matéria de educação, servindo de espaço de coordenação e avaliação de progresso na implementação de políticas. Nesta perspetiva, a União Europeia define que não pretende impor uma maior homogeneização ou unificação dos sistemas educativos nacionais. Mas, o argumento de Nóvoa (2005) é que o discurso europeu tende a impor-se como um ideal regulador que define as possibilidades e impossibilidades no campo da educação. Esta estratégia, de acordo com Nóvoa (1998), pressupõe um método e uma estrutura bem ilustrados pelos verbos: identificar, difundir, medir e comparar. Identificar objetivos comuns, difundir boas práticas, medir os resultados obtidos e comparar os progressos atingidos.

$\mathrm{Na}$ opinião de Ioannidou (2007) o que se passa atualmente é que na cooperação europeia em matéria de educação, não se visa unicamente construir um espaço europeu de educação, mas sim que os Estados-membros definam objetivos comuns que conduzem logicamente a um modelo europeu de educação.

Portanto, a União Europeia utiliza instrumentos, mecanismos e ferramentas para atingir certos objetivos políticos através dos quais exerce a sua regulação da educação. Através de atividades de monitorização, medição e comparação de resultados educativos e da avaliação de resultados e performances dos sistemas educativos, parece que tem vindo a emergir também no contexto da União Europeia uma tendência para uma regulação política da educação através de dados empíricos comparáveis.

Isto leva-nos a outra discussão que é o facto de, há já alguns anos, estarmos a assistir à construção de novos modos de regulação das políticas educativas. Tal como vimos anteriormente, a forma dominante hoje em dia constrói-se a partir dos grandes projetos estatísticos e dos indicadores da educação que, 
comparativamente, servem para avaliar e monitorizar o progresso dos sistemas de educação e de formação mundiais (PIS A, Education at a Glance, etc). Estas parecem ser as formas de regulação atuais mais influentes e importantes devido à sua conotação económica, porque os indicadores são instrumentos importantes para os Estados porque atraem o investimento externo, daí a necessidade de os países quererem estar bem qualificados nestes rankings mundiais.

Ioannidou (2007) analisa, também, os instrumentos de regulação utilizados pela OCDE e pela União Europeia em relação aos seus estadosmembros, como organizações com forte influência no espaço transnacional de educação. No caso da União Europeia, existe um instrumento de regulação muito claro, que é o Método Aberto de Coordenação que assenta numa abordagem a partir da monitorização e no benchmarking que avalia o progresso dos Estadosmembros em relação a objetivos comuns, a chamada "soft law" (Ioannidou, 2007). Por outro lado, este método também assenta na partilha de boas práticas que demonstra uma clara necessidade de avaliação pelos pares, no sentido de apoiar a aprendizagem mútua pela identificação de boas práticas. Temos ainda a emergência de uma série de estudos de comparação e avaliação em larga-escala, como é o caso da dos estudos desenvolvidos pelo Eurostat.

Estes exemplos, na opinião de Ioannidou (2007), são a prova de que existe uma certa convergência no uso e na racionalização destes instrumentos, justificados pela necessidade de informação e transparência sobre os sistemas educativos para possíveis comparações e identificação de casos de sucesso, para favorecerem a correção de políticas orientadas para objetivos comuns, baseados no conhecimento, enquanto meio de regulação.

É por isso que autores como Afonso (1998) chamam a atenção para o facto da avaliação ter sido uma forma de introduzir a lógica de mercado na esfera do Estado e da Administração Pública. A adoção deste tipo de políticas, levou a uma teoria de avaliação tipo positivista, e de avaliação a partir de indicadores mensuráveis, que é o reflexo dessa maior preocupação com o produto, do que com o processo.

A União Europeia aplica uma série de instrumentos de regulação das políticas educativas que embora baseados em consensos e em valores partilhados, desenvolvem uma série de ferramentas que recolhem e transformam informação em conhecimento, o que faz da União Europeia uma instituição com grande influência na mediação da política de educação comunitária. Neste sentido, é difícil de conceber a ideia de um Estado membro estar à margem desta estratégia política camuflada num discurso em torno de objetivos definidos em comum (Nóvoa, 1998) que constitui uma "gouvernance" europeia que define a maneira de colocar os problemas e de construir as políticas. 
Nesta linha de pensamento considera-se que é preciso aprofundar a análise dos processos de regulação das políticas educativas, no sentido de identificar e compreender não apenas a produção de regras, normas e constrangimentos, mas também o reajustamento das ações dos vários atores em relação a essas mesmas regras. Nesta perspetiva, parece fazer mais sentido falar de um processo de multi-regulação (Barroso, 2003) pois os processos de regulação em educação não resultam exclusivamente de uma imposição de normas definidas a priori, mas sim de diferentes lógicas e interpretações que resultam em processos de luta, confronto e negociação exercidos por atores institucionais, individuais e estruturas formais e informais que recombinam as várias regulações existentes, numa perspetiva de regulação social.

Neste perspetiva não se defende uma abordagem linear das políticas educativas, pois considera-se que a política é um processo sujeito a constantes reinterpretações, que vai sendo feita e refeita enquanto está a ser implementada. Dada esta constante recontextualização, defende-se a adoção de uma conceção mais alargada da política, como um processo, como um ciclo político entendido enquanto diversas arenas de ação (contexto de influência, contexto de produção de texto da política, contexto da prática) que engloba hoje processos e atores muito distintos (Antunes, 2006).

\section{O QUADRO ESTRATÉGICO EUROPEU PARA ENSINO SUPERIOR E A EDUCAÇÃO A DISTÂNCIA}

Através de um conjunto de estratégias e programas, a União Europeia tem como principal objetivo criar um enquadramento comum para os países europeus e para os seus sistemas de ensino superior que permita o intercâmbio entre estudantes e investigadores académicos no sentido de promover a excelência e a inovação no ensino e na investigação. Embora cada país tenha autonomia na definição das suas próprias políticas, a União Europeia assume um papel de orientação e apoio no desenvolvimento de uma estratégia comum que fomente a inovação e a excelência no ensino superior.

Parte-se do pressuposto que, através de capital humano altamente qualificado e a formação de cidadãos competentes, a Europa irá ter capacidades de criar emprego e ter um desenvolvimento económico próspero. Neste contexto, o papel das instituições de ensino superior é fundamental nesta estratégia e, nesse sentido o quadro estratégico europeu para o Ensino Superior defende que até 2020 cerca de $40 \%$ das pessoas com idades compreendidas entre os 30 e 0 s 34 anos deverão possuir um diploma de ensino superior ou equivalente. 
A estratégia onde se enquadram as orientações para os sistemas de ensino superior europeu é a Estratégia de Educação e Formação $2020^{1}$ que define uma nova agenda da União Europeia para o Ensino Superior que foi adotada pela Comissão Europeia em 2017 onde estão definidos conjunto de objetivos principais para a cooperação europeia em matéria de ensino superior:

- Combater futuras inadequações de competências e promover a excelência no desenvolvimento de competências;

- Criar sistemas de ensino superior inclusivos e ligados;

- Assegurar que as instituições de ensino superior contribuem para a inovação;

- Apoiar sistemas de ensino superior eficazes e eficientes.

É importante pensarmos o papel do ensino superior no contexto dos novos desafios e finalidades a que a União Europeia se propõe enfrentar, em particular, o papel da educação a distância.

Em 1996, Alan Tait publicava um artigo onde apresentava uma análise da Educação Aberta e a Distância na União Europeia durante os anos de 1985 e 1996. Desta sua análise Tait (1996) conclui que de uma entrada tímida nos documentos políticos da União Europeia em 1985, a Educação Aberta e a Distância passou a ser considerada, 10 anos depois, como sendo fundamental no reforço do papel que a educação e a formação desempenham no sucesso económico e na competitividade da União Europeia.

Também Hodgson (2002) analisou o impacto que o discurso sobre as tecnologias tem na Europa, concluindo que conceitos próximos da educação a distância, como o e-learning, estão cada vez a ocupar um lugar de maior destaque na retórica política da União Europeia.

A internacionalização do ensino superior tem sido uma das bandeiras emblemáticas da União Europeia desde os anos 90. Quer através de processos que facilitem a mobilidade de estudante se o reconhecimento de graus académicos na Europa (Processo de Bolonha), quer no sentido do estabelecimento de parcerias interinstitucionais que facilitem a cooperação entre instituições de ensino superior. Cada vez mais se verifica um movimento de pressão para a internacionalização destas instituições, que muitos referem como uma tendência para "desnacionalização" do ensino superior na Europa (Teichler, 1999). A Educação Aberta e o Acesso Aberto são outra das bandeiras discursivas da União Europeia, promovendo a flexibilidade e o acesso de todos à educação e formação, numa perspetiva de aprendizagem ao longo da vida. 
Em Portugal, desde 2006 que têm ocorrido transformações importantes no sistema de ensino superior. Desde logo, com a adoção do Processo de Bolonha neste ano. Mas vejamos um pouco, aquilo que Antunes (2017) sintetiza como os principais traços da trajetória do ensino superior português e da sua evolução:

- Nos anos 1999/2000 a expansão rápida e tardia;

- De 2000 a 2005 a expansão da resposta pública e a redução da oferta do sector privado;

- O aumento das taxas reais de escolarização de 2015 a 2015;

- A adoção do processo de Bolonha a partir de 2006;

- As políticas europeias, o aumento da emigração e a "fuga de cérebros" a partir de 2011 até 1015.

A autora realça ainda que, já em 2007 no relatório da OCDE sobre "Exames das políticas nacionais de educação: a educação terciária em Portugal" revelava uma tendência para considerar o ensino superior como uma vertente da política económica. Nessa linha, verificou-se que a partir de 2011, com a instalação da crise financeira e a consequente quebra orçamental se verificou a degradação do trabalho académico" (Antunes, p. 177).

Em 2017, 361.943 estudantes portugueses estão matriculados no ensino superior. Em 2016 os dados indicavam que 34,6\% da população entre os 30 e os 34 anos, tem como nível de escolaridade o ensino superior. Esta percentagem está, ainda, a baixo da média da União Europeia (28 países) cuja taxa é 39,1\%. Esta evidência deve.se, em grande medida, ao facto de nos últimos anos ter ocorrido uma estagnação devido à recessão económica que Portugal viveu com a presença da troika e o apoio financeiro externo providenciado pelo Banco Central Europeu, pelo Fundo Monetário Internacional e pela Comissão Europeia.

Verificamos assim, que as reformas no sistema de ensino superior português têm vindo a sofrer sérias alterações impulsionadas por agências internacionais, em grande medida protagonizada pela União Europeia que despoletaram uma séria de novas reformas.

No ano de 2017, por encomenda do governo português, a OCDE publica um relatório sobre o ensino superior português evidenciando alguns aspetos a melhorar, nomeadamente: a percentagem do PIB dedicada a este sistema de ensino tem de duplicar nos próximos 12 anos de modo a tingir os objetivos europeus; Portugal tem, assim, de investir mais e tem de definir uma estratégia que permita articular e ter impactos dos resultados da investigação e da inovação produzidas no ensino superior no desenvolvimento estratégico do país; é preciso valorizar mais os profissionais, a sua qualificação, bem como a qualificação dos portugueses, no geral; é preciso criar canais de acesso dos alunos provenientes do ensino profissional ao ensino superior, etc. 


\section{A POLÍTICA PORTUGUESA DE EDUCAÇÃO A DISTÂNCIA NO ENSINO SUPERIOR E O CASO DA UNIVERSIDADE ABERTA}

Atualmente, o ensino superior na europa (e no mundo) é caracterizado por uma proliferação de iniciativas e programas de educação a distância, que procuram captar estudantes não tradicionais e estudantes além-fronteiras. As universidades abertas são, por excelência, as pioneiras e as referências óbvias para a prática do ensino a distância, em rede, digital, nomeadamente em e-learning. Seria, então, de esperar que a especificidade das universidades abertas estivesse consagrada nos instrumentos de regulação das políticas nacionais, mas nem sempre assim acontece. Vejamos o caso português.

"Envolvidas em processos de mudança, frequentemente justificados por políticas difusas e medidas instrumentais avulsas, as instituições do Ensino Superior, ainda muito marcadas por uma cultura educativa tradicional e elitista, confrontam-se com a urgência de reinventarem o seu papel científico, social e educativo" (Caeiro e Aires, Jornal Público, 2018).

Uma das orientações importantes da União Europeia para o ensino superior dos seus estados-membros, nomeadamente o ensino superior português em matéria de educação a distância, prende-se com a "abertura da educação". Em 2013 a Comissão Europeia publica uma comunicação intitulada "Opening up Education: Innovative Teaching and Learning for All through New Technologies and Open Educational Resources". Neste documento é apresentado e discutido um conjunto de condições através das quais o ensino superior deverá ser desenvolvido para promover as oportunidades de aprendizagem que as tecnologias de informação oferecem. Outra mensagem presente nesta comunicação é que na Europa deverá existir um enquadramento político que estimule a introdução de práticas inovadoras de ensino e aprendizagem nas universidades e noutros espaços de educação e formação.

Em 2016 é publicada outra comunicação da Comissão Europeia intitulada "New Skills Agenda for Europe - Working Together to Strengthen Human Capital, Employability and Competitiveness". Neste documento defendese claramente que a aquisição e desenvolvimento de competências são essenciais para a modernização dos mercados de trabalho, sendo que uma das vias para atingir este objetivo é a aprendizagem ao longo da vida através da educação aberta. Foram assim estabelecidas novas prioridades para a Estratégia de Educação e Formação 2020, sendo que uma das prioridades é a educação inovadora e aberta. 
Com estas orientações a Comissão Europeia lança um conjunto de estímulos e conceitos orientadores da ação das instituições de ensino superior tais como educação em rede, educação aberta, educação online, cursos massivos e abertos, recursos educacionais abertos, etc.

Portugal tem vindo a assistir, nos últimos anos, por parte das instituições de ensino superior a várias iniciativas relacionadas com a educação a distância organizadas de forma avulsa e não integradas ou articuladas com estratégias políticas ou institucionais. Do ponto de vista governamental, não existe ainda regulamentação própria para o ensino superior a distância. Do ponto de vista institucional, muitas universidades portuguesas têm vindo a desenvolver ofertas formativas a distância, em particular na modalidade e-learning, mas sem qualquer suporte pedagógico definido, nem mesmo uma estratégia institucional para o ensino a distância. O único propósito é a captação de um maior público, em particular os estudantes de países de expressão portuguesa sendo que, na prática, as ofertas consubstanciam-se apenas na disponibilização de um conjunto de recursos numa plataforma de gestão de recursos online.

Do ponto de vista político, verifica-se uma total ausência de coordenação e regulamentação do ensino superior a distância. À margem de tudo isto, e numa tentativa constante de sobrevivência num sistema completamente adaptado ao ensino presencial, a Universidade Aberta portuguesa cumpre 30 anos de existência em 2018. Criada em 1988, a Universidade Aberta portuguesa assumese como uma referência no panorama europeu e internacional, em grande medida devido ao desenvolvimento do seu modelo e das suas práticas pedagógicas, além de outras vertentes. Desde 2007/2008 que a Universidade Aberta aplicou um modelo pedagógico orientado para o ensino em e-learning onde as atividades estão centradas no estudante, com base nos princípios da colaboração e da flexibilidade. Isto levou a uma profunda reorganização não só a nível pedagógico, como do ponto de vista orgânico, exigindo que todos os docentes obtivessem formação pedagógica específica. Como resultado a Universidade Aberta evoluiu, desenvolveu a sua oferta pedagógica, chegou a novos públicos, criou polos físicos de apoio aos estudantes em Portugal, e em alguns países de língua portuguesa. Assume-se como uma referência a nível europeu e mundial.

A única universidade pública portuguesa com ensino a distância online construiu uma memória histórica de 30 anos. A sua estrutura, a sua cultura organizacional, o seu modelo pedagógico, os seus estudantes, são características que a distinguem de todas as universidades de ensino superior português. Os seus estudantes, maioritariamente adultos inseridos no mercado de trabalho, de 
acordo com estudo "Resultados do questionário aos percursos laborais e de vida dos licenciados da UAb», revelaram que estão muito satisfeitos com o impacto do diploma quer na esfera pessoal, quer na esfera social e profissional das suas vidas.

Em termos nacionais, a Universidade Aberta, tem vindo a colaborar com várias instituições de ensino superior portuguesas no sentido de dar formação para a docência online, o que comprova a larga experiência e reconhecimento desta instituição.

Mas qual o papel da Universidade Aberta, a única instituição de ensino superior pública a distância em Portugal, no enquadramento político atual?

A resposta pode ser encontrada nas palavras de Domingos Caeiro e Luísa Lebres Aires ao afirmarem que "se, por um lado, a EaD se associa aos ideais de democracia, coesão social, igualdade de acesso à Educação ou da Aprendizagem ao Longo da Vida, os setores mais conservadores e grande parte das políticas que têm adotado têm sistematicamente ignorado o valor da $\mathrm{EaD}$ no quadro de mudança do Ensino Superior, traduzindo-se esta postura em silêncios ou em más decisões pautadas por uma discriminação negativa”. (Caeiro e Aires, Jornal Público, 2018).

Atualmente, a lei portuguesa não consagra formalmente o ensino a distância no panorama do ensino superior português. Isto quer dizer que, mesmo ao nível da acreditação de cursos, a agência responsável por esta função, avalia segundo os mesmos indicadores o ensino presencial e o ensino a distância.

Estes são alguns dos muitos constrangimentos que a Universidade Aberta portuguesa enfrenta atualmente. Mas o que se passará nos restantes países europeus e nas suas universidades de ensino a distância?

\section{REFLEXÕES FINAIS, NOVAS QUESTÕES E UMA PROPOSTA DE INVESTIGAÇÃO}

A resposta a esta questão implica um conjunto de reflexões e consequentes investigações que nos permitam um olhar holístico sobre um fenómeno multifacetado, com várias influências a vários níveis num contexto que se estende à escala global e que coloca grandes desafios aos sistemas de educação e formação.

A globalização económica trouxe à educação novas pressões ao nível da sua relação com o trabalho, visto que as lógicas neoliberais exigem uma maior e melhor formação de mão-de-obra qualificada, introduzindo lógicas de eficácia e de qualidade, de acordo com leis de concorrência e competitividade. Por outro lado, para além de formar cidadãos e trabalhadores, a educação formal e não formal tem agora de formar consumidores. Isto originou uma tendência para 
considerar a educação como uma mercadoria, um produto de troca que tem de ser vendável com maior eficácia ao menor custo, reduzindo o papel do Estado e introduzindo lógicas de avaliação e de comparabilidade.

A globalização política trouxe novos constrangimentos e pressões para a autonomia os Estados-Nação, obrigando-os a assumir um papel de reguladores ou mediadores, ao mesmo tempo que alargou a arena de decisão política a outros agentes que implicitamente ou explicitamente participam no processo de formulação da política educativa a vários níveis e sob diversas formas. Por outro lado, esta globalização política enfraqueceu a noção de cidadão como identidade nacional, para introduzir outras cidadanias como a cidadania global, ou a cidadania europeia, no caso da União Europeia. A globalização cultural trouxe uma tendência para a homogeneização e para a estandardização e ao mesmo tempo uma fragmentação cultural que tornou mais evidentes os confrontos entre a chamada cultura global e as culturas locais. É o chamado multiculturalismo que aproxima culturas distintas construindo um mosaico cultural onde se confrontam valores e crenças diversificados, o que traz à educação novos desafios como o respeito pela diversidade e pela diferença do outro.

Existe algum consenso sobre as influências neoliberais na esfera da educação por ação das organizações internacionais que impõem uma agenda educativa baseada em avaliações, financiamentos e estandardizações.

Alguns autores falam de uma crescente internacionalização das políticas educativas (Seixas, 2001) através de fenómenos de padronização e estandardização (Schriewer, 2000) apoiados por estas agendas globalmente estruturadas. Associados à globalização temos envolvidos no processo de formulação e implementação das políticas, outros atores que operam a outros níveis e que podem influenciar o sentido das políticas.

O campo de investigação das políticas educativas, neste contexto, tornase um campo extremamente complexo, visto ser uma arena de decisão constituída por vários níveis e onde intervêm diversos atores quer na formulação quer na implementação da política.

Dada esta complexidade, julgamos ser pertinente introduzir algumas definições de política, para compreendermos melhor os processos de produção da política e os novos contornos que tem vindo a assumir nos últimos anos.

Hoje em dia, podemos encontrar essencialmente duas tendências para conotar o termo política. Para uns, a política é a ciência normativa, conceptualizada como um programa de ação ou um conjunto de orientações que determinam como se deve proceder em certas circunstâncias particulares. Para outros, é a ciência do poder onde se analisam as relações que se estabelecem em torno de interesses que geram lutas pelo poder. 
Teodoro (2003) conclui que, o que estas duas definições partilham, é a ideia de que a política é um conjunto heterogéneo de elementos que envolve prescrições e orientações, compromissos, descontinuidades e omissões que importam conhecer. Ou seja, a política não é mais do que "o resultado, sempre provisório, de um processo de negociação assimétrico entre grupos e forças económicas, políticas e sociais, potencialmente conflituais" (2003, p. 14).

Recorrendo a Ball (2006) consideramos fundamental entender a política não apenas como um produto, mas também como um processo, ou seja a política encarada não apenas como a afirmação de valores e estratégias organizacionais e operacionais (produto), mas também como a capacidade de operacionalizar esses valores (processo).

Tendo em conta esta conceção de política apresentada como a capacidade de operacionalizar valores dentro de ambientes sociopolíticos particulares, entendemos o conceito de política como um produto (afirmação textual de valores e princípios) e um processo (o poder para formular afirmações textuais em práticas operacionais), onde diversos atores a diversos níveis conferem diferentes significados.

Portanto, embora existam discursos dominantes que tentam impor uma certa ordem de ideias e uma forma de pensar, existem também outros discursos discordantes e contraditórios que não podem ser excluídos das arenas de implementação política. Mas estes discursos são importantes para se conhecerem e analisarem pois eles espelham ideologias dominantes, regimes e crenças que ajudam a compreender a realidade social.

No contexto da União Europeia, verificamos que a economia baseada no conhecimento se tornou numa tendência e numa força bastante influente na política deste espaço político-económico, onde os sistemas educativos são instrumentos importantes para atingir este objetivo. As políticas educativas ligadas à economia do conhecimento constituem um discurso sobre a educação global do momento que circula sem referências ao contexto (Ozga e Lingard, 2007). Este discurso político promove uma agenda para a educação que uma série de ações e programas baseados na definição de objetivos comuns, avaliação por pares, competição, accountability e promoção de qualidade, que atuam como forças e processos de homogeneização.

No entanto, estas agendas globais, de acordo com Ozga e Lingard (2007), podem ser recontextualizadas e moldadas de acordo com contextos históricos, culturais, sociais, políticos e económicos particulares de cada Estado-nação.

Como vimos anteriormente, o ensino superior português tem vindo a ser alvo de constantes transformações impulsionadas por instrumentos de regulação política supranacional, como é o caso da União Europeia. No entanto, embora 
se proliferem os conceitos como a Educação em Rede, a Educação Aberta, a Educação Digital permanecem, ainda, situações de apatia e indefinição, como é a regulamentação política portuguesa da educação a distância. A discussão gerada em torno destes conceitos ainda não contaminou a opinião pública que se mantém um pouco desconfiada do ensino a distância. $O$ governo português ainda pouco ou nada faz para inverter esta situação, esquecendo o papel e a importância do ensino a distância na sociedade atual.

As orientações supranacionais da União Europeia para o ensino superior influenciaram profundas alterações no sentido uniformizar e facilitar o reconhecimento de graus e estimular a mobilidade, apelando à competitividade e ao aumento das qualificações. Neste enquadramento legitimam-se algumas opções políticas e esquecem-se outras.

Considerando a situação portuguesa e a ausência de regulação política para a educação a distância no ensino superior, seria importante investigar o panorama político de outros países desta união. Será a situação portuguesa relativa à ausência de enquadramento legal para a educação a distância no ensino superior única e exclusiva nesta união de países? Nos países que têm estratégias políticas e enquadramentos legais definidos para a educação a distância, nomeadamente no ensino superior, como estão a operacionaliza-los? Que significados e papéis atribuem à educação a distância no ensino superior?

Com base nestas questões, propomos desenvolver uma investigação com base num modelo de análise da política que demonstre a sua complexidade, partindo do princípio que a direção estratégica deriva de uma agenda globalmente estruturada, mas que vai sendo reformulada à medida que é traduzida em princípios organizacionais e práticas operacionais.

Em trabalhos anteriores (Neves, 2009) procurámos analisar e comparar estratégias políticas de Aprendizagem ao Longo da Vida (ALV) em vários países da União Europeia. Concluímos que existe uma diversidade de estratégias políticas de ALV nos países analisados, muito influenciadas pelos contextos históricos, económicos, sociais, políticos e culturais donde emergem, nem sempre convergentes com a matriz discursiva da União Europeia.

Verificando a situação portuguesa no que respeita ao ensino superior a distância e o seu vazio legal, seria importante perceber como estão outros países europeus a desenvolver as suas políticas de educação a distância para o ensino superior e quais os significados que vão reintroduzindo nessas políticas. A proposta de investigação consubstancia-se, numa primeira fase, numa análise descritiva de vários contextos de educativos onde pretenderemos analisar alguns dados estatísticos e indicadores que nos permitam caracterizar a performance dos sistemas educativos nacionais de alguns países europeus, no que respeita 
ao ensino superior; posteriormente propomo-nos analisar o ambiente político que caracteriza a educação a distância de cada país. Nessa fase iremos identificar as agendas e as principais iniciativas dos governos dos países analisados e que estratégias políticas definem para a educação a distância no ensino superior, procurando descrever as principais características dos documentos políticos enquadradores dessas estratégias; finalmente tentaremos desenvolver uma análise comparativa das estratégias de educação a distância no ensino superior presentes nos documentos políticos e dos aspetos estruturais que dizem respeito à educação a distância nos países analisados.

O objetivo dessa investigação será a comparação das estratégias políticas de educação a distância no ensino superior de alguns países europeus a partir dos dados recolhidos da análise de conteúdo dos documentos políticos. Nesse sentido, iremos proceder à justaposição dos dados recolhidos para cada categoria de análise para que possamos tecer algumas comparações e examinar algumas semelhanças e diferenças resultantes da justaposição. Depois da justaposição, segue-se a comparação, onde se examinam as diferenças e as semelhanças. Nesta fase, para além da união entre os elementos a comparar acrescenta-se um outro elemento que é o critério que, segundo o qual, fazemos a comparação. Segundo Pedró e Velloso (1991), a qualidade de um bom trabalho de comparação depende da consistência e da qualidade deste critério. O critério de comparação é a estrutura teórica que permite a quem compara emitir juízos de valor acerca das similaridades e das diferenças dos factos ou fenómenos comparados. Finalmente teremos a interpretação, onde iremos procurar estabelecer relações entre os elementos que recolhemos sobre as estratégias de educação a distância no ensino superior e os fatores sociais, culturais, históricos e económicos de cada país. Com isto pretendemos tecer elações e conclusões, produzindo um novo conhecimento.

Através deste plano de trabalho, procurar-se-á desenvolver uma análise comparativa em relação à implementação de estratégias políticas de educação a distância em alguns países e as orientações gerais da União Europeia para esta área. Tentaremos, também, perceber se as dinâmicas de educação a distância desenvolvidas em cada país espelham mais a influência das orientações da União Europeia, ou se evidenciam mais influências nacionais, ou de outra ordem.

Com esta proposta de investigação terminamos esta reflexão reconhecendo que é importante conhecer diferentes realidades políticas nacionais para compreender a natureza dinâmica e complexa dos processos políticos. Mesmo numa configuração política singular, como é o caso da União Europeia, convivem diferentes interpretações e práticas de orientações supranacionais. Conhecer os contextos numa perspetiva histórica, económica, social e cultural pode-se revelar fundamental para compreender a opção pela ausência ou não de 
políticas definidas para algumas áreas da educação, como é o caso da educação a distância.

Os contributos desta proposta de investigação que aqui deixamos, serão brevemente divulgados, acreditando que poderão desvendar alguns dos sentidos para as diferentes opções políticas orientadas para a educação a distância no ensino superior.

\section{REFERÊNCIAS}

Abrantes, P. (coord.) et al. (2016). Resultados do questionário aos percursos laborais e de vida dos licenciados da UAb. Lisboa: Universidade Aberta. Disponível em: https://repositorioaberto.uab.pt/bitstream/10400.2/4997/1/ Relatorio_Percursos\%20Diplomados\%20UAb_jan2016.pdf

Afonso, A. J. (1998). Políticas Educativas e Avaliação Educacional: para uma análise sociológica da reforma educativa em Portugal 1985-1995. Braga: Universidade do Minho.

Antunes, F. (2006). Governação e Espaço Europeu de Educação: Regulação da educação e visões para o projecto "Europa". Revista Crítica de Ciências Sociais (75), 63-93. Disponível em: https://repositorium.sdum.uminho.pt/ bitstream/1822/24468/1/RCCS\%2075\%20FAntunes.pdf

Antunes, F. (2017). Uma trajetória singular? Apontamentos sobre europeização, privatização e especificidades do ensino superior português. Revista Eletrônica de Educação, v.11, n.1, 165-184. Disponível em: http://www.reveduc.ufscar.br/ index.php/reveduc/article/view/2096

Ball, S. (2006). Education policy and social class. London and New York: Routledge.

Barroso, J. (2003). Regulação e desregulação nas Políticas Educativas: tendências emergentes em estudos de educação comparada. In J. Barroso (Ed.), A Escola pública - regulação, desregulação, privatização. Porto: Edições ASA. 
Caeiro, D. \& Aires, L. (2018). Democracia, Ensino Superior e novos públicos: a educação a distância. Artigo de opinião publicado no Jornal Público dia 22 de fevereiro de 2018. Disnponível em: https://www.publico.pt/2018/02/22/ sociedade/opiniao/democracia-ensino-superior-e-novos-publicos-a-educacao-adistancia-1804015

Hodgson, V.E. (2002), The European Union and e-learning: an examination of rhetoric, theory and practice. Journal of Computer Assisted Learning, 18: 240-252. Doi:10.1046/j.0266-4909.2002.00236.x

Ioannidou, A. (2007). A Comparative Analysis of New Governance Instruments in the Transnational Educational Space: a shift to knowledge-based instruments? European Educational Research Journal, 6, 336-347. Disponível em: http:/ / journals.sagepub.com/doi/pdf/10.2304/eerj.2007.6.4.336

Neves, C. (2009). Estratégias de aprendizagem ao longo da vida na União Europeia: análise crítica e comparativa das estratégias de aprendizagem ao longo da vida de cinco estados-membros. Tese de Doutoramento. Monte da Caparica: FCT/UNL.

Nóvoa, A. (1998). Histoire et Comparaison. Essais sur l'Éducation. Lisboa: Educa.

Nóvoa, A., \& M. Lawn (Coords), (2005). L'Europe Réinventée. Regards Critiques sur l'espace européen de l'éducation. Paris: L'Harmattan.

Ozga, J. \& Lingard B. (2007). Introduction: reading education policy and politics. In B. Lingard \& J. Ozga (Eds.), The RoutledgeFalmer Reader in Education Policy and Politics. London and New York: Routledge.

Pedró, F. \& A. Velloso (1991). Manual de Educación Comparada. Barcelona: PPU.

Schriewer, J. \& A. Nóvoa (2000). A difusão mundial da escola: Alunos professores - currículo - pedagogia. Lisboa: Educa. 
Seixas, A. M. (2001). Políticas Educativas para o Ensino Superior: A globalização neoliberal e a emergência de novas formas de regulação estatal. In Transnacionalização da Educação. Da crise da Educação à "Educação" da crise. Porto: Edições Afrontamento.

Tait, A. (1996). Open and distance learning policy in the European Union 1985-1995. Higher Education Policy. September 1996, Volume 9, Issue 3, pp 221-238. Doi: https://doi.org/10.1016/S0952-8733(96)00014-1

Teichler, U. (1999). Internationalisation as a challenge for higher education in Europe. Tertiary Education and Management Vol. 5, Iss. 1, pp 5-23: Doi: https://doi.org/10.1080/13583883.1999.9966978

Teodoro, A. (2003). Globalização e Educação. Políticas Educacionais e novos modos de governação. Porto: Edições Afrontamento.

CLÁUDIA NEVES é doutorada em Ciências da Educação pela Faculdade de Ciências e Tecnologia da Universidade Nova de Lisboa. Desde 2010 é professora auxiliar na Universidade Aberta. E-mail: claudia.neves@uab.pt

Recebido em março de 2018

Aprovado em abril de 2018 